\title{
Competition and Advertising in Medicine
}

\section{Dr Yam Bahadur Roka}

MS, M.Ch., IFAANS

The world is progressing rapidly and so is medical sector not only in terms of technology but also in the sheer number of doctors and specialist completing their training each year. With the senior physicians still practicing, updating knowledge, getting training and skills, and venturing to new frontiers of medical treatment there remains a fierce yet, hidden competition amongst us to be the better. Plain degrees, fellowship, specialized training or courses or the backup of both government or private / corporate hospitals are not enough to satisfy the needs of some of us. This has led to advertisements by both the hospital and the physician to exceed in this competition.

Previous methods of paper, newspaper, hoarding, boarding and magazine advert has now given way to Internet and most of the public start their search via the latter. Such practice was found to be common in the younger generation, plastic surgeons and in those that cater to large geographical area of practice. ${ }^{2}$ Female physicians, board certified, internal medicine, pediatrics and surgeons are equal in terms of advertising. ${ }^{4}$ another study showed that education and income had no relationship with attitude but the patients recalled if seen on the TV or newspaper. ${ }^{1}$ There are different laws that define the result of false medical advertising. Physicians may sue other who are falsely advertising about the procedure or results and the patient can also sue if the advertising was false. ${ }^{3}$

So the question remains is this advertising justified or what are the ways to do so?

Remain within Ethics: This happens when there are false claims in either the facility, center, equipment, results or success claims, training or experience of the physician and sometimes based on racial or gender. Unless expressed by the patient or relatives do not brand as "the best", "the only one", "first time", "world class", "latest", "international collaboration",etc but do provide your qualification and your experience. Do not refer patients to other center or even abroad for the sake of money when the same treatment can be done locally or within the country.

Promoting a specific medicine/method: It's a misconception that the drug brand is written by a physician because they are paid so by the pharmaceutical company in either cash, gifts, travel or personal favors. Always justify the use of drugs in not only treating but also questioning whether it's really needed. Do not highlight the beneficiary effect of one brand name over other with the same generic formula unless its been done by the Drug administration or government. Similarly creating fear or doubts in the patients mind regarding untimely use of some particular drug, radiological or hematological investigation and even procedure is unethical.

Promotion by pseudo-patients: Many times, there are claims by so called patients who give detailed benefit and cure under a particular drug or center or doctor or procedure. These pseudo-patients are unethical and violate the need for patient confidence. Paying the media in praise of your center or practice by use of pseudo-patients, videos, images, social media apps and recorded messages are also to be discouraged. Payments made to referring party, ambulance drivers and insurance agents in response to bringing patients needs to be stopped.

Criticizing competitors: This is usually done openly in meetings or conferences either by personal statements or using adverts locally that criticize and defame local center or doctors. It also happens when the patient goes for second opinion to another doctor. Saying, "it's too late", "you should have come earlier", "this medicine or procedure was not needed", "the other doctor has treated wrongly" are some of the ways for defamation. Its better to update your website regarding your experiences and success rates. Proper referral system within the country will help guide patients for best care.

Physician advertising is always not negative and can be used to bring changes in health care management. It can be used to improve the quality of care by proper statements of the procedure, newer techniques, equipment's, availability of trained and qualified physicians locally.

This can help the public to choose their physician or center and avoid getting trapped by quacks. This can also help physicians for proper referral of their patients to specialist centres for best outcome. It reduces the need for unwanted investigations and many times the urge to travel to another city or country for treatment saving time and money.

\section{References:}

1. Andaleeb SS. How consumers view hospital advertising. J Hosp Mark 8 (2): 73-85, 1994

2. Folland ST. Advertising by physicians. Behavior and attitudes. Med Care 25 (4):311-26, 1987

3. Hirsch BD, Wilcox DP. Remedies by competitors for false advertising. Tex Med 86 (5):61-2, 1990

4. Rizzo JA. Physician advertising revisited. Med Care 26 (12):1238-44, 1988 